\title{
CÂN BẰNG NƯỚC LƯU VỰC SÔNG VU GIA - THU BỒN BẰNG MÔ HİNH MIKE HYDRO BASIN
}

\author{
Vũ Thị Thu Lan', Hoàng Thanh Sơn², Nguyễn Bách Tùng ${ }^{3}$, \\ Đào Bích Thuỹ ${ }^{4}$, Nguyễn Thị Hải Yến ${ }^{2}$
}

Tóm tắt: Liên tiếp trong các năm gần đây, tình trạng thiếu nước sủ dụng cho các hoạt động nhu cấp sinh hoạt cho dân cu và các dịch vu du lịch ở TP Đà Nã̃ng và TP Hội An thuờng xuyên xảy ra, diện tích đất nông nghiệp ở các khu vục đồi và đồng bằng bị hạn hán mở rộng... Nghiên cứu ứng dụng mô hình MIKE HYDRO basin áp dụng cho LVS Vu Gia - Thu Bồn nhằm đánh giá thưc trạng thiếu nước sử dụng trên cơ sở cân bằng nguồn nước với nguyên tắc phân chia các tiểu lư vục theo thể tụ nhiên. Kết quả tính toán cho thấy vấn đề thiếu nước sủ dụng tập trung ở vùng ha du (ha du Vu Gia, hạ lưu Thu Bồn, Vĩnh Điện, Ly ly, Truờng Giang) mà nguyên nhân là nguồn cấp nuớc không đảm bảo (bao gồm cả luợng và chất luợng). Đối với các khu vục trung du, tình trạng thiếu nước là do thiếu công trình khai thác.

Từ khóa: Vu Gia- Thu Bồn, MIKE HYDRO Basin, Cân bằng nước, thiếu nước sư dụng.

Ban Biên tập nhận bài: 12/10/2019 Ngày phản biện xong: 22/11/2019 Ngày đăng bài: 25/12/2019

\section{1. Đặt vấn đề}

Lưu vực sông (LVS) Vu Gia - Thu Bồn là một trong bốn lưu vực sông lớn nhất miền Trung, chảy qua Kon Tum và đổ ra biển thuộc địa phận TP Đà Nẵng và Quảng Nam và là lưu vực có vị thế địa chính trị thuận lợi, nguồn tài nguyên thiên nhiên phong phú, đa dạng sinh học... và được đánh giá là lưu vực có tiềm năng nguồn nước phong phú nhất Việt Nam với tổng lượng dòng chảy trung bình nhiều năm đạt 20,4 tỷ $\mathrm{m}^{3}$ tương ứng với lớp dòng chảy $2060 \mathrm{~mm}$ (gấp hơn 2 lần trung bình lớp dòng chảy toàn Việt Nam) [9], thừa ẩm cho sự phát triển của sinh vật [7]. Đây là điều kiện thuận lợi để phát triển nên trên lưu vực đã có lịch sử xã hội lâu đời từ thương cảng Hội An, thánh địa Mỹ Sơn đến nay là tâm điểm của vùng kinh tế trọng điểm miền Trung với TP Đà Nẵng năng động và tỉnh Quảng Nam đang tiến vượt bậc về kinh tế - xã hội [12-13].
Sự tương tác giữa hoàn lưu và điều kiện địa hình nên có tới trên $60 \%$ tài nguyên nước (nước mưa và nước sông suối) tập trung trong $3-4$ tháng mùa mưa lũ và thời kỳ khô hạn kéo dài, do đó đây cũng là nơi xuất hiện nhiều thiên tai liên quan đến dòng chảy trong đó hạn hán, thiếu nước sử dụng đã trở nên thiên tai thường xuyên và ngày càng tác động mạnh mẽ đến sự phát triển của lưu vực [8]. Liên tiếp trong các năm gần đây, tình trạng thiếu nước sử dụng cho các hoạt động trên lưu vực như thiếu nước cấp sinh hoạt cho dân cư và các dịch vụ du lịch ở TP. Đà Nẵng và TP. Hội An, diện tích đất nông nghiệp ở các khu vực đồi và đồng bằng bị hạn hạn mở rộng... đã khiến cho các cơ quan quản lý của địa phương công bố tình trạng hạn hán khẩn cấp (Quảng Nam 2015 - 2016) [17] và đưa ra Phương án ứng phó khẩn cấp trong 24 giờ để điều tiết nguồn nước từ các hồ chứa thủy điện nhằm khôi phục cấp nước sinh hoạt trên địa bàn TP Đà Nẵng (TP.

${ }^{1}$ Ban Úng Dụng, Viện Hàn lâm Khoa họ và Công nghệ Việt Nam

${ }^{2}$ Viện Địa lý, Viện Hàn lâm Khoa hoc và Công nghệ Việt Nam

${ }^{3}$ Trung tâm Động lục học Thuỷ khi Môi trường

${ }^{4}$ Viện kỹ thuật nhiệt đới, Viện Hàn lâm Khoa hoc và Công nghệ Việt Nam

Email:hoangson97@gmail.com 
Đà Nẵng 2018 - 2019) [16]. Để đánh giá thực trạng thiếu nước sử dụng, việc tiến hành cân bằng nguồn nước đối với lưu vực sông là hết sức cần thiết. Hiện nay có rất nhiều các mô hình toán mô phỏng cân bằng nguồn nước nhưng qua phân tích các dữ liệu về điều kiện địa lý tự nhiên cũng như phương thức sử dụng nguồn nước của cộng đồng dân cư trên LVS, bài báo chọn mô hình MIKE HYDRO basin áp dụng cho LVS Vu Gia - Thu Bồn. Đây là mô hình toán đã được sử dụng rộng rãi cho các LVS trên lãnh thổ Việt Nam nói chung và cho các LVS dải ven biển Trung Bộ nói riêng với việc mô phỏng các tiểu lưu vực gắn liền với các công trình khai thác nước [11], vì vậy chưa phản ánh được cán cân nước tự nhiên trên LVS. Bài báo đưa ra phương pháp phân chia các tiểu lưu vực dựa trên thể tự nhiên để đánh giá cân bằng nước trong mô hình $\mathrm{MIKE}$ HYDRO BASIN nhằm xác định cụ thể về các hạn chế sử dụng nước trong từng tiểu lưu vực, từ đó đưa ra cơ sở khoa học cho việc điều chỉnh sử dụng nhằm giảm thiểu hạn hán thiếu nước dùng trên LVS.

\section{Cơ sở dữ liệu và phương pháp nghiên cứu}

\subsection{Giới thiệu khu vục nghiên cúu}

Lưu vực sông Vu Gia - Thu Bồn Nằm trong $107^{\circ} 00$ - $108^{\circ} 30$ kinh độ Đông $15^{\circ} 00$ - $16^{\circ} 00$ vĩ độ Bắc, có diện tích là $10.350 \mathrm{~km}^{2}$ (hình 1$)$. Lưu vực sông được giới hạn phía Bắc bởi dãy núi Bạch Mã - một nhánh núi đâm ra biển ở phần cuối dãy Trường Sơn Bắc là đường phân nước với sông Hương thuộc tỉnh Thừa Thiên Huế, phía Tây là dãy Trường Sơn Nam có đỉnh cao nhất địa hình phía Nam lãnh thổ nước ta (đỉnh Ngọc Linh cao $2598 \mathrm{~m}$ ). Về mặt diện tích LVS Vu Gia - Thu Bồn chiếm tương đương 84,5\% diện tích của tỉnh Quảng Nam, 43,9\% diện tích thành phố Đà Nẵng (tương đương với $425 \mathrm{~km}^{2}$ ) và $5,1 \%$ diện tích tỉnh Kon Tum (tương đương với $\left.525 \mathrm{~km}^{2}\right)$.



Hình 1. Vị trí địa lý LVS Vu Gia - Thu Bồn

Địa giới hành chính LVS Vu Gia - Thu Bồn gồm 13 huyện của tỉnh Quảng Nam là Trà My, Tiên Phước, Phước Sơn, Hiệp Đức, Nam Giang, Quế Sơn, Duy Xuyên, Hiên, Đại Lộc, Điện Bàn, một phần của huyện Thăng Bình [4] và thành phố Đà Nẵng là quận Cẩm Lệ, Ngũ Hành Sơn, Sơn Trà, một phần huyện Hoà Vang, quận Thanh Khê [3], cùng một phần của vùng núi phía thượng lưu của huyện DakGlei tỉnh Kon Tum. Địa hình của LVS Vu Gia - Thu Bồn bị phân chia mạnh và nghiêng từ Tây sang Đông với đầy đủ các loại hình như núi, đồi, đồng bằng châu thổ và cát ven biển, kết hợp với chế độ hoàn lưu đã tạo nên cảnh quan đa dạng và phong phú của LVS với rất nhiều đặc thù [5]. Địa hình đồng bằng ven biển là dạng địa hình tương đối bằng phẳng, ít biến đổi, có độ cao dưới $30 \mathrm{~m}$, tập trung chủ yếu ở phía Đông lưu vực, hình thành từ sự tích tụ trầm tích cổ (khu vực Đại Lộc, Hòa Vang, Sơn Trà, Ngũ Hành Sơn, Điện Bàn, Duy Xuyên, 
Thăng Bình, Hội An) [9].

Về khí hậu, LVS Vu Gia - Thu Bồn có nền nhiệt độ cao (không có mùa lạnh, ngoại trừ một số núi cao trên $1000 \mathrm{~m}$ ở phía Tây Bắc và Tây Nam của LVS), nhiệt độ trung bình năm thấp nhất vào tháng 12 hoặc tháng 1 và cao nhất vào tháng 6 , tháng 7 [1]. Hình thái LVS tạo thành hình phễu với 3 mặt là núi (Bắc - Tây - Nam) đã đưa đến lượng mưa ở đây rất lớn, trên LVS có tồn tại tâm mưa lớn Trà Mi (vượt trên 3.500 $\mathrm{mm} / \mathrm{năm}$ ). Mùa mưa kéo dài từ 4 tháng (đối với các khu vực ở phía Đông) đến 9 tháng (đối với khu vực tâm mưa Trà My). Theo đó, LVS Vu Gia - Thu Bồn có nguồn tài nguyên nước phong phú nhất Việt Nam với moduyn dòng chảy trung bình năm gấp 2 lần so với trung bình toàn lãnh thổ, theo chỉ số Falkenmark (FI) [6] trung bình toàn lưu vực đạt khoảng $10.000 \mathrm{~m}^{3} /$ người.năm (tính đến năm 2018) và vượt xa ngưỡng "không căng thẳng về nước" (FI $>1.700 \mathrm{~m}^{3} /$ người.năm). Tuy nhiên dư thừa nước tập trung cao vào các tháng mùa lũ và đã trở thành loại hình thiên tai lũ lụt có tác động bất lợi nhất đối với lưu vực sông. Còn các tháng mùa kiệt, dòng chảy giảm và chịu tác động của xâm nhập mặn từ cửa sông vì vậy nơi đây cũng thường xuyên chịu tác động của việc hạn hán thiếu nước dùng.

\subsection{Co' sở dĩu liệu}

\begin{tabular}{|c|c|c|c|c|c|}
\hline \multirow{2}{*}{ TT } & \multirow{2}{*}{ Tên Trạm } & \multicolumn{2}{|c|}{ Vị trí } & \multirow{2}{*}{$\begin{array}{c}\text { Yếu tố quan } \\
\text { trắc }\end{array}$} & \multirow{2}{*}{$\begin{array}{l}\text { Thời gian chuỗi } \\
\text { đánh giá }\end{array}$} \\
\hline & & Kinh độ & Vĩ độ & & \\
\hline 1. & Bà Nà & $107^{\circ} 59^{\prime}$ & $16^{\circ} 00^{\prime}$ & $\mathrm{X}$ & $1980-1995$ \\
\hline 2. & Cẩm Lệ & $108^{\circ} 02^{\prime}$ & $16^{\circ} 00^{\prime}$ & $\mathrm{X}, \mathrm{H}$ & $1980-2018$ \\
\hline 3. & Tiên Sa & $108^{\circ} 25^{\prime}$ & $16^{\circ} 10^{\prime}$ & $\mathrm{X}$ & $1980-2009$ \\
\hline 4. & Hòa Bắc & & & & $2009-2016$ \\
\hline 5. & Ái Nghĩa & $108^{\circ} 07^{\prime}$ & $15^{\circ} 53^{\prime}$ & $\mathrm{X}, \mathrm{H}, \mathrm{Q}$ & $1980-2018$ \\
\hline 6. & Hội Khách & $107^{\circ} 49^{\prime}$ & $15^{\circ} 49^{\prime}$ & $\mathrm{X}, \mathrm{H}$ & $1980-2018$ \\
\hline 7. & Thăng Bình & $108^{\circ} 20^{\prime}$ & $15^{\circ} 45^{\prime}$ & $\mathrm{X}$ & $1980-1996$ \\
\hline 8. & Vĩnh Điện & $108^{\circ} 24^{\prime}$ & $15^{\circ} 89^{\prime}$ & $\mathrm{X}$ & $1980-1988$ \\
\hline 9. & Hiên & $107^{\circ} 39^{\prime}$ & $15^{\circ} 55^{\prime}$ & $X$ & $1980-2018$ \\
\hline 10. & Thành Mỹ & $107^{\circ} 50^{\prime}$ & $15^{\circ} 46^{\prime}$ & $\mathrm{X}, \mathrm{H}, \mathrm{Q}$ & $1980-2018$ \\
\hline 11. & Nông Sơn & $108^{\circ} 03^{\prime}$ & $15^{\circ} 42^{\prime}$ & $\mathrm{X}, \mathrm{H}, \mathrm{Q}$ & $1980-2018$ \\
\hline 12. & Giao Thuỷ & $108^{\circ} 01^{\prime}$ & $15^{\circ} 48^{\prime}$ & $\mathrm{X}, \mathrm{H}, \mathrm{Q}$ & $1980-2018$ \\
\hline 13. & Câu Lâu & $108^{\circ} 17^{\prime}$ & $15^{\circ} 51^{\prime}$ & $\mathrm{X}, \mathrm{H}$ & $1980-2018$ \\
\hline 14. & Hội An & $108^{\circ} 20^{\prime}$ & $15^{\circ} 52^{\prime}$ & $\mathrm{X}, \mathrm{H}$ & $1980-2018$ \\
\hline 15. & Tiên Phước & $108^{\circ} 18^{\prime}$ & $15^{\circ} 29^{\prime}$ & $\mathrm{X}$ & $1980-2018$ \\
\hline 16. & Quế Sơn & $108^{\circ} 13^{\prime}$ & $15^{\circ} 42^{\prime}$ & $\mathrm{X}$ & $1980-2016$ \\
\hline 17. & Khâm Đức & $107^{\circ} 47^{\prime}$ & $15^{\circ} 26^{\prime}$ & $\mathrm{X}$ & $1980-2016$ \\
\hline 18. & Hiệp Đức & $108^{\circ} 06^{\prime}$ & $15^{\circ} 34^{\prime}$ & $\mathrm{X}, \mathrm{H}$ & $1980-2018$ \\
\hline 19. & Phước Sơn & & & $\mathrm{X}$ & $2016-2018$ \\
\hline 20. & Trà My & $108^{\circ} 13^{\prime}$ & $15^{\circ} 20^{\prime}$ & $X, Z$ & $1980-2018$ \\
\hline 21. & Tam Kỳ & $108^{\circ} 29^{\prime}$ & $15^{\circ} 33^{\prime}$ & $\mathrm{X}, \mathrm{H}, \mathrm{Z}$ & 2011-2018 \\
\hline 22. & Đà Nẵng & $108^{\circ} 12^{\prime}$ & $16^{\circ} 02^{\prime}$ & $\mathrm{X}, \mathrm{Z}$ & $1980-2010$ \\
\hline
\end{tabular}


+ Số liệu khí tượng thủy văn: Nghiên cứu sử dụng số liệu của 22 trạm quan trắc khí tượng (2 trạm khí tượng, 20 trạm đo mưa), 12 trạm quan trắc thủy văn (2 trạm cấp 1 và 10 trạm cấp 3$)$ đo đạc số liệu thủy văn bao gồm các yếu tố nhiệt độ, độ ẩm, mưa, bốc hơi, mực nước, lưu lượng... có thời gian liên tục từ năm 1980 đến năm 2018 $[1,12,13]$.

+ Số liệu dân sinh kinh tế

- Dữ liệu về công trình thủy điện (thông số hồ chứa, quy trình vận hành), thủy lợi khai thác nguồn nước đã đi vào hoạt động tính đến năm 2017.

- Niên giám thống kê của TP. Đà Nẵng và tỉnh Quảng Nam năm 2010 và 2017 [3, 4].

+ Các tài liệu về bản đồ các yếu tố mặt đệm $[12,13]$

- Bản đồ địa hình lưu vực sông Vu Gia - Thu Bồn tỷ lệ từ 1/10.000, 1/25.000.

- Các bản đồ chuyên đề như phân bố mưa trung bình năm, mùa kiệt, tài nguyên nước, địa chất, địa mạo, thổ nhưỡng, thực vật...

\subsection{Phưong pháp sử dụng}

2.2.1. Phuoong pháp tính toán nhu cầu sủ dụng nước

Nhu cầu nước dùng được tính toán theo các hộ sử dụng nước trên lưu vực như: sinh hoạt, nông nghiệp, công nghiệp, dịch vụ - du lịch và các hoạt động đô thị, duy trì và bảo vệ môi trường và được xác định theo các định mức quy định của Quốc gia.

Nước dùng cho sinh hoạt: là lượng nước người dân ở đô thị, nông thôn sử dụng và được tính toán theo Quy chuẩn kỹ thuật QCVN: 01/2008/BXD.

Nước dùng cho hoạt động đô thị và thương mại du lịch: Nhu cầu nước cho khu vực thương mại, dịch vụ và du lịch tính bằng $15 \%$ lượng nước dùng cho sinh hoạt. Nhu cầu nước cho các hoạt động đô thị tính bằng 50\% lượng nước cho sinh hoạt.

Nước dùng cho công nghiệp: Với mục tiêu tính tổng quát về nhu cầu nước, các tác giả sử dụng định mức theo Quy chuẩn kỹ thuật QCVN: 01/2008/BXD.

Nước dùng cho nông nghiệp bao gồm nhu cầu nước để tưới tiêu cho cây trồng và lượng nước uống cho gia súc và gia cầm.

- Căn cứ vào đặc tính cây trồng và điều kiện tự nhiên ở khu vực, báo cáo sử dụng mô hình cropwat được Bộ Nông nghiệp và phát triển nông thôn khuyến khích sử dụng [TCVN 9170:2012].

- Nước phục vụ chăn nuôi được tính toán theo Tiêu chuẩn nước cho chăn nuôi gia súc, gia cầm của Bộ Nông nghiệp và phát triển nông thôn.

Nước dùng cho nuôi trồng thủy sản: Nuôi trồng thủy sản ở đây xét đến việc sử dụng nước ngọt để nuôi thủy sản nước lợ (tôm sú, tôm thẻ chân trắng...) [10].

Duy trì dòng chảy tối thiểu hạ du: Được xác định theo hướng dẫn của Thông tư số 64/2017/TT-BTNMT ngày 22/12/2017 về xác định dòng chảy tối thiểu trên sông, suối và hạ lưu các hồ chứa, đập dâng.

\subsubsection{Phương pháp mô hình toán mô phỏng} cân bằng nước

Cân bằng nước biểu thị mối quan hệ giữa lượng nước đến, lượng nước đi và lượng trữ lại ở một khu vực, một lưu vực hoặc của một hệ thống trong điều kiện tự nhiên hay có việc can thiệp của con người. Như trên đã trình bày, bài báo sử dụng mô hình MIKE HYDRO basin để đánh giá cân bằng nước trong LVS làm cơ sở đề xuất các giải pháp sử dụng nước hợp lý với sơ đồ tình toán trình bày trong hình 2 . 




Hình 2. So đồ phương pháp tính toán cân bằng nước

\subsubsection{Thiết lạp mô hình}

Đối với LVS Vu Gia - Thu Bồn việc phân chia các tiểu lưu vực dựa vào tiêu chí sau:

+ Dựa trên đặc điểm tự nhiên, sự phân cắt của địa hình tạo nên các tiểu lưu vực có tính độc lập tương đối được bao bọc bởi các đường sông hoặc các đường phân thủy.

+ Căn cứ theo ranh giới hành chính được xem xét theo góc độ quản lý nhà nước và quản lý hệ thống công trình khai thác nước

+ Tiểu lưu vực được hình thành vừa là một hộ dùng nước trong hiện tại đồng thời sẽ là một hộ dùng nước trong tương lai; có đủ điều kiện để xác định các nút lấy nước, thoát nước, xả nước... góp phần xây dựng được sơ đồ phát triển nguồn nước toàn lưu vực.

+ Các tiểu lưu vực đều có tính độc lập tương đối trong quản lý khai thác tài nguyên nước và có liên hệ với các tiểu lưu vực khác.

Theo đó, dựa trên bản đồ địa hình, mạng lưới sông và mạng lưới các công trình thủy điện, thủy lợi khai thác nước trên sông sử dụng công cụ phần mềm Mapinfo đã phân chia LVS Vu Gia Thu Bồn thành 19 tiểu lưu vực cân bằng nước gồm 6 tiểu lưu vực được khống chế tại các công trình hồ thủy điện như: TĐ A Vương, TĐ Sông Bung 4, TĐ Sông Côn 1, TĐ Sông Côn 2, TĐ Đắk Mi 4, TĐ Sông Tranh 2 và 13 lưu vực khu giữa, hạ lưu (hình 3 ).

\section{Kết quả và thảo luận}

\subsection{Xác định nhu cầu sử dụng nước}

Trên cơ sở các định mức tính toán mục 2.2.1, số liệu thống kê ở mục 2.1.2 đã xác định được nhu cầu sử dụng nước trung bình tháng và năm của các năm điển hình theo các vùng đã được phân chia ở mục 2.2.3. Trong tính toán nhu cầu của các hộ sử dụng nước, các hệ số sau đây được áp dụng:

- Hệ số tưới của hệ thống lấy ứng với tần suất mưa $75 \%$

- Đối với sinh hoạt lấy mức đảm bảo là 95\%.

- Đối với sản xuất điện năng lấy mức đảm bảo là $85 \%$.

- Nước cho hoạt động đô thi lấy bằng 50\% nhu cầu nước sinh hoạt, du lịch lấy bằng $15 \%$.

Nước duy trì dòng chảy, đảm bảo môi trường và đẩy mặn lấy vùng hạ du được sử dụng theo kết quả đề tài "Nghiên cứu xác định khả năng chịu tải và dòng chảy tối thiểu của sông $\mathrm{Vu}$ gia - Thu Bồn" [13]. 


\section{BÀI BÁO KHOA HỌC}

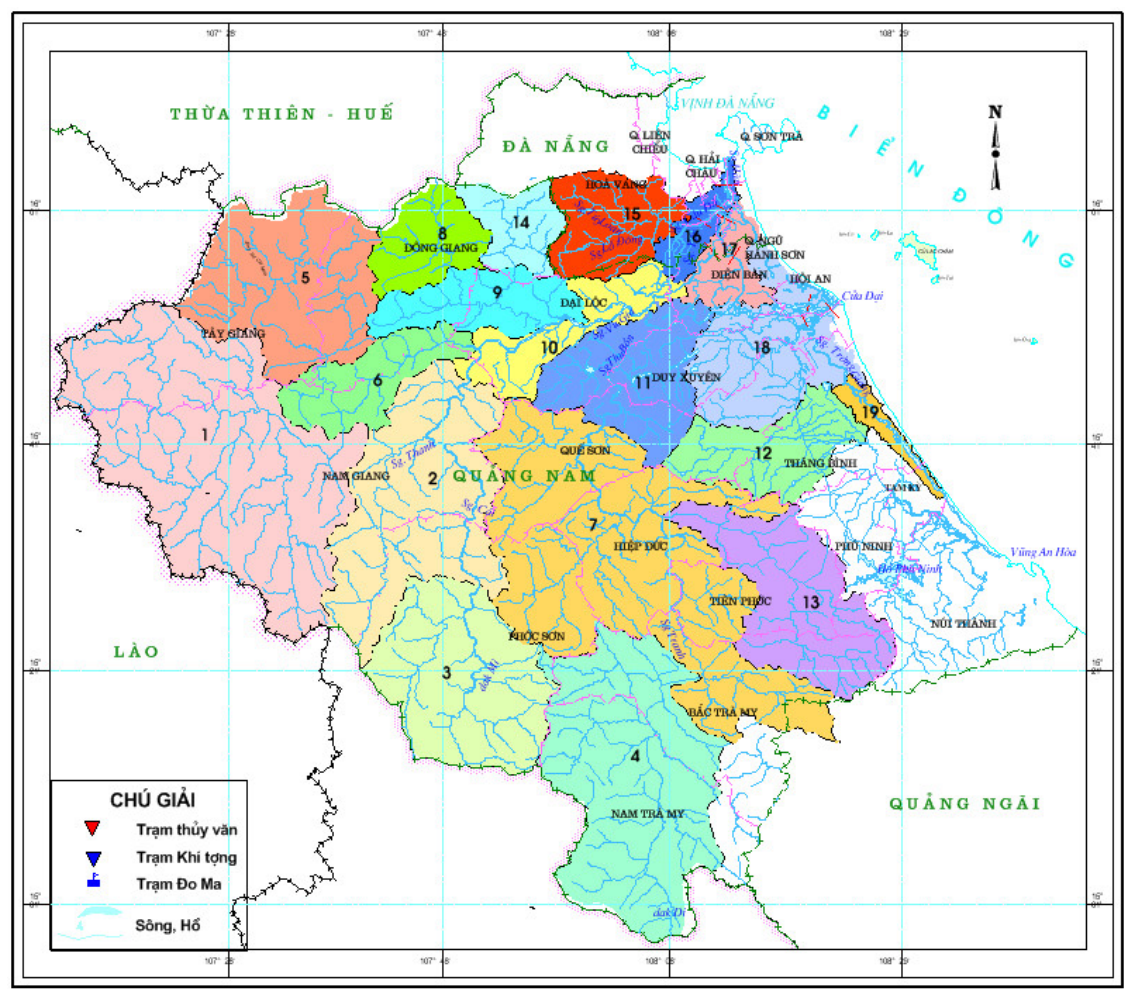

Hình 3. Phân chia tiểu lưu vục trong mô hình MIKE HYDRO Basin

Bảng 1. Tổng nhu cầu sủ dụng nước tù̀ năm 2008 - 2017 của các tiểu lưu vục

\begin{tabular}{clcccccccccc}
\hline \multirow{2}{*}{$\begin{array}{c}\text { Ký } \\
\text { hiệu }\end{array}$} & Tiểu lưu vực & \multicolumn{7}{c}{ Tổng nhu cầu sử dụng nước theo các năm (triệu m ${ }^{3}$ ) } \\
\cline { 2 - 12 } & 2008 & 2009 & 2010 & 2011 & 2012 & 2013 & 2014 & 2015 & 2016 & 2017 \\
\hline 1 & Sông Bung & 7,44 & 7,32 & 7,39 & 8,45 & 8,64 & 8,99 & 8,97 & 9,37 & 9,77 & 10,2 \\
2 & Thành Mỹ & 11,4 & 11 & 10,7 & 12,8 & 13,1 & 13,5 & 13,3 & 13,9 & 14,5 & 15 \\
3 & Đăk Mi 4 & 6,32 & 6,53 & 6,67 & 7,53 & 7,95 & 7,89 & 8,29 & 8,38 & 8,47 & 8,57 \\
4 & S. Tranh 2 & 21,5 & 23,6 & 22,7 & 21,8 & 22,2 & 24 & 28,1 & 28,1 & 28,1 & 28,1 \\
5 & A Vương & 11,8 & 12,1 & 12,5 & 15,2 & 16,8 & 19 & 19,8 & 20,1 & 20,4 & 20,8 \\
6 & Sông Bung 4 & 20,7 & 20,1 & 19,8 & 24 & 25,6 & 28,4 & 28,5 & 29,3 & 30,1 & 30,9 \\
7 & Nông Sơn & 73,9 & 72,5 & 72,5 & 88,4 & 95,1 & 97,8 & 99,5 & 99,6 & 99,7 & 99,8 \\
8 & Sông Côn 2 & 3,54 & 3,57 & 3,74 & 4,62 & 4,62 & 4,64 & 4,67 & 4,99 & 5,3 & 5,62 \\
9 & Sông Côn & 21,5 & 21,5 & 22,2 & 20,7 & 20,8 & 20,8 & 20,9 & 21,4 & 21,9 & 22,4 \\
10 & TL_Vu Gia & 34,2 & 34 & 35,3 & 32,8 & 33,0 & 33,0 & 33,1 & 33,9 & 34,7 & 35,5 \\
11 & TL_Thu Bon & 129,5 & 130,3 & 133,4 & 124 & 125,2 & 123,9 & 125,3 & 122 & 118,7 & 115,5 \\
12 & Sông Ly Ly & 114,7 & 115,7 & 118,7 & 108,4 & 108,9 & 108,2 & 111,2 & 113 & 114,9 & 116,7 \\
13 & Nông Sơn 1 & 42,4 & 41,6 & 41,4 & 39,7 & 44,1 & 44,5 & 46,7 & 46,4 & 46 & 45,7 \\
14 & Sông Côn 1 & 4,68 & 4,72 & 4,92 & 6,14 & 6,15 & 6,17 & 6,22 & 6,66 & 7,09 & 7,52 \\
15 & Túy Loan & 20,9 & 20,8 & 26,5 & 25,5 & 24,3 & 24,7 & 24,2 & 24,6 & 24,9 & 25,3 \\
16 & HL_VG & 96,6 & 98,1 & 118,8 & 115,4 & 117,1 & 117,8 & 120,3 & 142,9 & 165,6 & 188,3 \\
17 & Vĩnh Điện & 51,1 & 52,4 & 53,6 & 51 & 50,5 & 49,3 & 49,5 & 46,7 & 150,3 & 152 \\
18 & HL_VGTB & 150,4 & 151,1 & 157,9 & 142,5 & 143,6 & 142 & 146,8 & 148,5 & 43,9 & 41,1 \\
19 & Trường Giang & 25,1 & 25,3 & 26,2 & 24,1 & 24,3 & 24,2 & 24,4 & 25,1 & 25,8 & 26,5 \\
\hline
\end{tabular}


Tổng nhu cầu dùng nước trên các tiểu lưu vực từ năm 2008 đến 2017 (bảng 1) cho thấy nhu cầu nước hàng năm đến nay đạt dưới 1 tỷ $\mathrm{m}^{3}$ nước (chiếm khoảng dưới 5\% tổng lượng nước đến) và tăng khoảng $1,5 \%$ tuy nhiên biến động trong từng tiểu lưu vực rất khác nhau. Đối với các tiểu lưu vực có công trình thủy điện đi vào vận hành (A Vương, Sông Côn, Sông Bung, Đakmi 4...), nhu cầu sử dụng nước tăng nhanh, trên $4 \% /$ năm, thậm trí tới $9 \% /$ năm. Bên cạnh đó tiểu lưu vực có khu đô thị, công nghiệp phát triển nhu cầu sử dụng nước có xu thế tăng mạnh đến 65/năm như hạ lưu sông Vu Gia (TP Đà Nẵng). Đối với các khu vực phát triển nông nghiệp xu hướng sử dụng nước giảm do giảm nhu cầu nước cho



ngành nông nghiệp như đối với tiểu lưu vực Vĩnh Điện, trung và hạ lưu Vu Gia - Thu Bồn... Kết quả thể hiện nhu cầu nước đối với ngành nông nghiệp chiếm tỷ trọng rất lớn trong việc khai thác nguồn nước LVS Vu Gia - Thu Bồn.

\subsection{Cân bằng nước}

Tính toán dòng chảy đến: Dòng chảy đến các tiểu lưu vực trong mô hình được xác định từ mô hình NAM cho liệt năm 1980 - 2017, mô phỏng trong thời gian từ 1980 - 1995, kiểm định trong thời gian từ 1996 - 2010. Kết quả được trình bày trong bảng 2 cho thấy đã xác định được bộ thông số mô hình mưa - dòng chảy phù hợp với điều kiện của LVS Vu Gia - Thu Bồn.



Hình 4. Kết quả hiệu chỉnh và kiểm định lưu lương cho 2 trạm Nông Sơn và Thành Mỹ: (a) Nông Son (1980-1995); (b) Thành Mỹ (1980-1995); (c) Nông Son (1996-2010);

(d) Thành Mỹ (1996-2010)

Bảng 2. Hiệu chỉnh và kiểm định cho 2 trạm Nông Sơn và Thành Mỹ

\begin{tabular}{lccc}
\hline \multirow{2}{*}{ Trạm } & \multicolumn{2}{c}{ Chỉ tiêu Nash(\%) } & \multirow{2}{*}{ Kết quả } \\
\cline { 2 - 3 } & Hiệu chỉnh & Kiểm định & \\
\hline Nông Sơn & 88,9 & 88,6 & Tốt \\
Thành Mỹ & 78,4 & 78,9 & Tốt \\
\hline
\end{tabular}

Dựa vào lượng mưa năm được lựa chọn, sử dụng bộ thông số mô hình xác định tính toán dòng chảy đến tự nhiên cho 19 tiểu lưu vực đối với năm 2008. Đối với thời kỳ sau năm 2009, ngoài số liệu dòng chảy tính từ mưa có số liệu vận hành hồ chứa của các công trình thủy điện trên từng tiểu lưu vực.

\subsection{Hiệu chỉnh mô hình cân bằng nước}

Để chuẩn hóa bài toán, hiệu chỉnh mô hình MIKE HYDRO Basin cho năm 2008 với sơ đồ 


\section{BÀI BÁO KHOA HỌC}

tính toán và lấy lưu lượng từ tháng 1 - 12 tại 2 trạm thủy văn Nông Sơn và Thành Mỹ kiểm tra. Kết quả tính toán được thể hiện trên hình



(a) cho thấy sự phù hợp với bộ thông số mô hình MIKE HYDRO Basin trong cân bằng nguồn nước LVS Vu Gia - Thu Bồn.

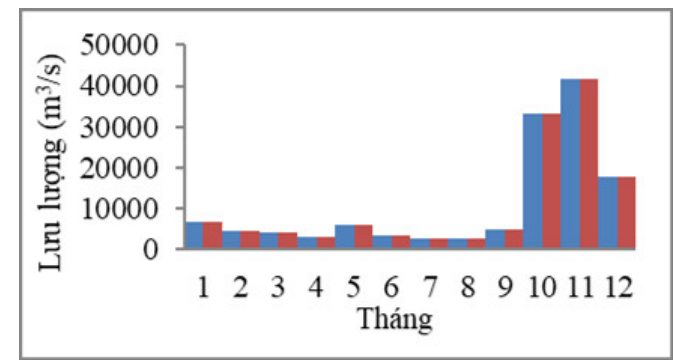

(b)

Hình 5. Biểu đồ kết quả tính toán cân bằng nước năm 2008 tại các trạm:

(a) Thành Mỹ; (b) Nông Sơn

3.4 Kiểm định mô hình cân bằng nước

Sau khi hiệu chỉnh mô hình MYHYDRO Basin cho năm 2008, với các thông số giả lập ở

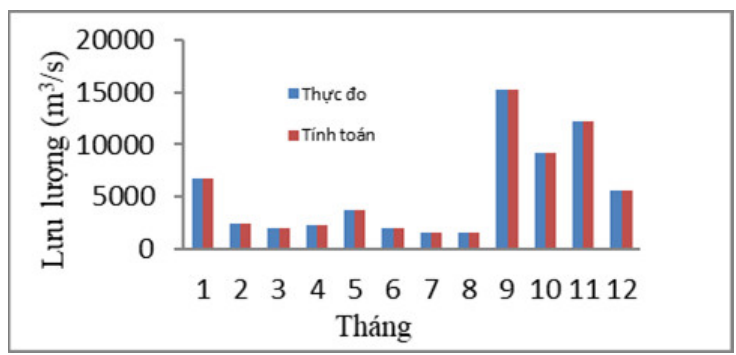

(a) trên lấy để kiểm định cho năm 2009. Kết quả được thể hiện ở hình 6 .



(b)

Hình 6. Biểu đồ kết quả tính toán cân bằng nước năm 2009 tại 02 trạm:

(a) Thành Mỹ; (b) Nông Sơn

Như vậy có thể thấy rằng qua thử dần cho thấy kết quả hiệu chỉnh và kiểm định tốt, vì vậy bộ thông số đã xác định phù hợp để sử dụng tính toán cân bằng nước cho các năm tiếp theo và theo các kịch bản về nhu cầu sử dụng nước của LVS Vu Gia - Thu Bồn.

Do các công trình trên lưu vực được xây dựng theo các năm khác nhau, việc đưa công trình vào trong mô hình để tính toán sẽ ảnh hưởng đến kết quả tính. Vì vậy, bài toán chia nhỏ giai đoạn tính cho từng năm xuất hiện công trình như sau (hình $6)$.

+ Giai đoạn năm 2008: Điều kiện cân bằng tự nhiên;

+ Giai đoạn năm 2009 - 2010 khi cả lưu vực có hồ thủy điện $\mathrm{A}$ Vương và Sông Côn 2 hoạt động;
+ Giai đoạn 2011 khi có 3 hồ thủy điện A Vương, Sông Côn 2, Sông Tranh 2 hoạt động;

+ Giai đoạn năm 2012 - 2013 khi cả lưu vực có hồ thủy điện $\mathrm{A}$ Vương và Sông Côn 2, Sông Tranh 2, Đắk Mi 4 hoạt động;

+ Giai đoạn năm 2014 đến nay có 5 hồ chứa lớn A Vương, Sông Côn 2, Sông Tranh 2, Đắk Mi 4, Sông Bung.

Dòng chảy đến tính toán của từng tiểu lưu vực từng năm sẽ được đưa vào mô hình MIKE HYDRO Basin tiến hành cân bằng nguồn nước.

Áp dụng bộ thông số xác định mô phỏng cân bằng nước tại các tiểu lưu vực với điều kiện mưa, hoạt động của các công trình điều tiết nước từng năm và nhu cầu nước đã được tính toán ở bảng 1 , xác định lượng nước thiếu cho các tiểu lưu vực trình bày trong bảng 2 và hình 7 . 




Hình 7. So đồ tính toán trong mô hình MIKE HYDRO basin

Bảng 2. Tổng lương nước thiếu theo mô hình MIKE HYDRO basin

\begin{tabular}{lcccccccccc}
\hline \multirow{2}{*}{ Tiểu vùng } & \multicolumn{10}{c}{ Tổng lượng nước thiếu (triệu $\mathrm{m}^{3}$ ) } \\
\cline { 2 - 11 } & 2008 & 2009 & 2010 & 2011 & 2012 & 2013 & 2014 & 2015 & 2016 & 2017 \\
\hline Sông Bung & 0 & 0 & 0 & 0 & 0 & 0 & 0 & 0 & 0 & 0 \\
Thành Mỹ & 0 & 0 & 0 & 0 & 0 & 0 & 0,38 & 0 & 0 & 3,4 \\
Đăk Mi 4 & 0 & 0 & 0 & 0 & 0 & 0 & 0 & 0 & 0 & 0 \\
S. Tranh 2 & 0 & 0 & 0 & 0 & 0 & 0 & 0 & 0 & 0 & 0 \\
A Vương & 0 & 0 & 0 & 0 & 0 & 0 & 0 & 0 & 0 & 0 \\
Sông Bung 4 & 0 & 0 & 0 & 0 & 0 & 0 & 0 & 0 & 0 & 0 \\
Nông Sơn & 0 & 0 & 15,02 & 0 & 0 & 0 & 0 & 0 & 0 & 0 \\
Sông Côn 2 & 0 & 0 & 0 & 0 & 0 & 0 & 0 & 0 & 0 & 0 \\
Sông Côn & 0 & 0 & 0,95 & 0 & 0 & 0 & 0 & 0 & 0 & 0,44 \\
TL_Vu Gia & 0 & 0 & 0 & 0 & 0 & 1,8 & 3,35 & 0 & 0 & 0 \\
TL_Thu Bon & 0 & 1,51 & 27,51 & 1,56 & 49,01 & 52,59 & 0 & 0 & 6,3 & 12,66 \\
Sông Ly Ly & 17,38 & 12,97 & 33,33 & 24,4 & 23,54 & 27,56 & 27,01 & 15,12 & 9,99 & 13,63 \\
Nông Sơn 1 & 0 & 0 & 0,25 & 0 & 0 & 0 & 0 & 0 & 0 & 2,03 \\
Sông Côn 1 & 0 & 0 & 0 & 0 & 0 & 0 & 0 & 0 & 0 & 0 \\
Túy Loan & 0 & 0 & 0,19 & 0 & 0 & 0 & 0 & 0 & 0 & 0 \\
HL_VG & 0 & 0 & 0 & 0 & 5,6 & 20,6 & 22,9 & 23,5 & 5,64 & 16,61 \\
Vĩnh Điện & 0 & 1,81 & 5,5 & 2,35 & 0,64 & 1,79 & 4,7 & 0,78 & 0,38 & 0 \\
HL_TB & 0,16 & 8,64 & 45,56 & 3,03 & 41,6 & 60,28 & 0 & 0 & 0 & 0 \\
Trường Giang & 2,56 & 3,12 & 6,8 & 4,43 & 3,89 & 4,84 & 5,95 & 4,29 & 3,36 & 3,08 \\
\hline
\end{tabular}

Như vậy, các tiểu lưu vực thiếu nước chủ yếu 2012 khi thủy điện ĐakMi 4 đi vào hoạt động, nằm ở khu vực trung lưu và hạ lưu ven biển của LVS và các thời kỳ thiếu nước cũng rất khác nhau. Đối với các tiểu lưu vực thuộc dòng chính còn đối các tiểu lưu vực thuộc sông Thu Bồn, thiếu nước diễn ra vào thời đọan trước, từ năm 2009 - 2013, điều này thể hiện sự gia tăng nguồn Vu Gia, các năm thiếu nước diễn ra sau năm nước bên sông Thu Bồn khi tiếp nhận nguồn 


\section{BÀI BÁO KHOA HỌC}

nước từ thủy điện ĐakMi; 3 tiểu lưu vực luôn thiếu nước mặc dù có khá nhiều công trình khai thác nước cung cấp là tiểu LVS Vĩnh Điện, Ly Ly và Trường Giang, đây là các khu vực có nguồn nước tại chỗ hạn chế, luôn chịu tác động tiếp nguồn của các khu vực khác nên khó chủ động nguồn nước (hình 8). Thời gian thiếu nước xuất hiện nhiều nhất (từ tháng 3 - 8) ở vùng hạ du sông $\mathrm{Vu}$ Gia, các khu vực còn lại thiếu trong 4 tháng.



Hình 8. So đồ các khu vục thiếu nước sủ dụng

Để kiểm định kết quả tính toán từ mô hình Mike Hydro Basin, chúng tôi sử dụng tài liệu thống kê hạn hán do TP Đà Nẵng [15] và tỉnh Quảng Nam [17] cung cấp và dữ liệu điều tra xã hội học về thực trạng hạn hán ở các khu vực thuộc trung và hạ lưu LVS của đề tài [12-13], cho thấy:

+ Về vấn đề cấp nước cho ngành nông nghiệp: Tình trạng thiếu nước cấp cho sản xuất nông nghiệp lưu vực đã ảnh hưởng khoảng 13.000ha đất nông nghiệp thuộc các địa phương như Hòa Vang (Đà Nẵng), Duy Xuyên; Điện Bàn; Đại Lộc; TP. Hội An và Thăng Bình (Quảng Nam); trong đó, diện tích bị thiếu hụt nguồn nước trên hệ thống sông Vu Gia 8.500 ha; trên sông Thu Bồn 4.500 ha.

+ Về vấn đề cấp nước cho sinh hoạt cộng đồng dân cư và ngành công nghiệp: Hầu hết nguồn nước sinh hoạt trên lưu vực được khai thác từ nguồn nước mặt và trong những năm gần đây các nguồn nước cấp cho các khu đô thị quan trọng như TP Đà Nẵng và TP Hội An thường xuyên thiếu. Liên tục những năm 2013 đến nay, nước sinh hoạt luôn là vấn đề bức xúc đối với các đô thị này, cao điểm đã phải đưa ra các “phương án ứng phó khẩn cấp trong 24 giờ để điều tiết nguồn nước từ các hồ chứa thủy điện nhằm khôi phục cấp nước sinh hoạt trên địa bàn TP Đà Nẵng”" [16] và đã có hình thức luân phiên điều tiết cấp nước trên mạng lưới cho các khu vực nước thiếu và yếu cũng như lắp đặt các bồn chứa nước tạm trên địa bàn để phần nào khắc phục tạm thời tình trạng "khát nước" đang diễn ra gay gắt tại khu vực tập trung dày đặc các cơ sở lưu trú du lịch ven biển này.

Như vậy có thể thấy rằng kết quả tính toán từ mô hình MIKE HYDRO Basin phù hợp với thực trạng hạn hán thiếu nước dùng trong khu vực.

Theo đánh giá về hiểm họa hạn hán cho thấy trên LVS Vu Gia - Thu Bồn [2] hiện nay có bảy tiểu lưu vực không có nguy cơ hạn hán nằm ở vùng núi của hệ thống, nơi nhu cầu nước chủ yếu cho phát điện, còn các nhu cầu cho nông nghiệp và sinh hoạt rất thấp. Những tiểu lưu vực ở phần trung lưu (5 tiểu lưu vực) có nguy cơ thấp với mức thiếu hụt nước thấp chủ yếu do thiếu các 
công trình khai thác nước do sự chênh lệch độ cao giữa mặt nước và mặt đất vì vậy diện tích phụ thuộc vào nước mưa còn lớn, thiếu hụt sẽ xuất hiện trong những năm khô hạn. Đối với các khu vực nằm ở hạ lưu (đồng bằng và vùng cát ven biển), nguy cơ thiếu nước cao. Đây là khu vực dân cư sống tập trung, thuận lợi cho việc phát triển các ngành kinh tế (nông nghiệp, công nghiệp, dịch vụ du lịch...) vì vậy lượng nước thiếu ở các vùng này cũng lớn hơn so với các vùng thiếu nước khác. Nguồn cấp nước ở đây chủ yếu thông qua các trạm bơm lấy nước tại chỗ trên sông vì vậy khi nguồn nước ngọt từ thượng nguồn giảm đồng thời cũng làm tăng xâm nhập mặn đã làm giảm khả năng khai thác nguồn nước cho các hoạt động ở đây.

\section{Kết luận}

Mô hình MIKE HYDRO Basin được hiệu chỉnh và kiểm định phù hợp với điều kiện $\mathrm{LVS}$ $\mathrm{Vu}$ Gia - Thu Bồn nhằm mô phỏng được thực trạng hán hán thiếu nước dùng của từng tiểu lưu vực đặc thù. Kết quả tính toán cho thấy vấn đề thiếu nước sử dụng tập trung ở khu vực hạ du LVS (vùng đồng bằng và cồn cát ven biển) mà nguyên nhân là nguồn cấp nước không đảm bảo (bao gồm cả lượng và chất lượng), trong đó có phần tác động của các công trình thủy điện phía thượng du. Đối với các khu vực trung du, tình trạng thiếu công trình khai thác là nguyên nhân gây hạn hán ở các tiểu lưu vực này.

Việc phân chia các tiểu lưu vực theo thể tự nhiên trong bài toán cân bằng nước cũng đã phản ánh được nguyên nhân của tình trạng hạn hán trong LVS. Các tiểu LVS Vĩnh Điện, Trường Giang có nhu cầu nước cho ngành nông nghiệp chiếm tỷ trọng rất cao vì vậy để giảm thiểu thiệt hại, cần chuyển đổi cơ cấu cây trồng, mùa vụ, áp dụng các phương pháp tưới nước tiết kiệm trong sản xuất nông nghiệp, cân đối phát triển công nghiệp với lượng nước hiện có của tiểu lưu vực nhằm giảm lượng nước thiếu hụt. Tiểu vùng hạ lưu Vu Gia lượng nước thiếu do tăng nhanh nhu cầu sử dụng và có sự biến động trong phân phối dòng chảy giữa sông $\mathrm{Vu}$ Gia và sông Thu Bồn, biện pháp giảm thiểu là điều chỉnh quy trình vận hành liên hồ chứa phần thượng du LVS, đồng thời sử dụng nguồn nước tại chỗ của TP. Đà Nẵng theo định hướng linh hoạt [14].

Lời cám ơn: Cảm ơn đề tài "Nghiên cưu ưng dụng công nghệ phòng chống xói lở bò̀ sông Vu Gia - Thu Bồn tỉnh Quảng Nam” đã cung cấp số liệu để thực hiện bài viết này.

\section{Tài liệu tham khảo}

1. Đinh Phùng Bảo (2017), Xây dựng công nghệ dụ báo dòng chảy cạn, xâm nhập mặn cho hệ thống sông Vu Gia - Thu Bồn. Tạp chí Khí tượng Thủy văn, 682, 48-55.

2. Bruun, Ole, Casse, Thorkil (Editors) (2013), On the Frontiers of Climate and Environmental Change: Vulnerabilities and Adaptation in Central Vietnam, Springer Verlag, Berlin.

3. Cục Thống kê TP Đà Nẵng (2018), Niên giám thống kê TP Đà Nã̃ng năm 2017, Nxb Thống kê, Hà Nội.

4. Cục Thống kê tỉnh Quảng Nam (2018), Niên giám thống kê tỉnh Quảng Nam năm 2017, Nxb Thống kê, Hà Nội.

5. Nguyễn Lập Dân (2008), Đề xuất các giải pháp phòng tránh, giảm thiểu các tai biến thiên nhiên cho lư vục sông Thu Bồn - Vu Gia. Tạp chí Các khoa học về trái đất, 30 (1), 2008.

6. Falkenmark, M. \& other (1989), Macro scale water scarcity water scarcity requires microscale approaches: aspects of vulnerability in semi-arid development. Natural Resources Forum, 13 (4), 258-267.

7. Phạm Quang Hạnh (1984), Dòng chảy sông ngòi Việt Nam, nxb Khoa học kỹ thuật, Hà Nội.

8. Vũ Thị Thu Lan (2013), Nghiên cứu biến động của thiên tai (lũ lụt và hạn hán) ở tỉnh Quảng 


\title{
BÀI BÁO KHOA HỌC
}

Nam trong bối cảnh biến đổi khi hậu. Tạp chí Các khoa học về trái đất, 35 (1) tháng 3 năm ,P 6674.

9. Vũ Thị Thu Lan (2019), Phát triển mô hình Delta cảnh báo xâm nhập mặn các sông vùng hạ lưu lưu vực Vu gia - Thu bồn. Tạp chí Khoa học và Công nghệ, Tập 61 số (6) tháng 6 năm, P 17-23.

10. Nguyễn Phú Quỳnh (2015), Phưong pháp tính toán hệ số cấp nuoớc cho tôm vùng ven biển đồng bằng sông Cửu Long. Tạp chí Khoa học và Công nghệ Thủy lợi, 29, 1-8.

11. Hoàng Thanh Sơn (2013), Úng dụng mô hình Mike Basin xác định cân bằng nước trên lưu vục sông Cái Phan Rang. Tạp chí Các khoa học về trái đất, 35 (1), tháng 3 năm, P 75-80.

12. Hoàng Thanh Sơn (2018), Nghiên cứu đề xuất giải pháp kiểm soát xâm nhập mặn cho Thành phố Đà Nã̃ng. Báo cáo tổng kết đề tài KHCN Độc lập cấp Nhà nước, mã số ĐLCN36/16, Cục thông tin KHCN, Hà Nội.

13. Hoàng Thanh Sơn (2018), Nghiên cưu diễn biến xâm nhập mặn (đất và nước) vùng ven biển tỉnh Quảng Nam, đề xuất giải pháp úng phó. Báo cáo tổng kết đề tài KHCN tỉnh Quảng Nam, lưu trữ tại Trung tâm Công nghệ thông tin và truyền thông Quảng Nam.

14. Nguyễn Văn Tỉnh (2016), Nghiên cứu xác định khả năng chịu tải và dòng chảy tối thiểu của sông Vu gia - Thu bồn. Báo cáo tổng kết đề tài KHCN Trọng điểm cấp Nhà nước, Cục thông tin KHCN, Hà Nội.

15. Văn phòng Ban chỉ đạo Ứng phó với biến đổi khí hậu thành phố Đà Nẵng (2016), Đánh giá toàn diện nhằm hướng đến khả năng chống chịu với biến đổi khi hậu đối với nguồn tài nguyên nước TP Đà Nã̃ng. Báo cáo tổng kết dự án Quỹ Rockefeller.

16. UBND TP Đà Nẵng (2019), Công văn số 5661/UBND-STNMT ngày 21/08/2019.

17. UBND tỉnh Quảng Nam (2016), Phưong án phòng chống hạn và nhiếm năm trên địa bàn tỉnh Quảng Nam. Quyết định số 731/QĐ-UBND ngày 29/02/2016.

18. UBND tỉnh Quảng Nam (2017), Quy hoạch thủy lợi tỉnh Quảng Nam đến năm 2025 và định huớng đến năm 2030. Quyết định số 1695/QĐ-UBND ngày 16/05/2017.

\section{WATER BALANCE IN VU GIA - THU BON RIVER BASIN BY USING MIKE HYDRO BASIN MODEL Vu Thi Thu Lan', Hoang Thanh Son², Nguyen Bach Tung ${ }^{3}$, Dao Bich Thuy ${ }^{4}$, Nguyen Thi Hai Yen ${ }^{2}$ \\ ${ }^{1}$ Department of Application \& Development of Technology, Viet Nam Academy of science and Technology \\ ${ }^{2}$ Institute of Geography, Viet Nam Academy of science and Technology \\ ${ }^{3}$ Center for Environmental fluild dynamics \\ ${ }^{4}$ Institute for Tropical Technology}

\begin{abstract}
In recent years, there has been a shortage of water for activities such as daily life activities and tourism services in Da Nang and Hoi An, where the hills and plains have been expanded by drought. The article selected the MIKE HYDRO basin model to apply to Vu Gia - Thu Bon river basin to assess the situation of water shortage in use on the basis of balancing water sources with natural resources. The principle of division of sub-basins is natural. Calculation results show that the problem of lack of water is concentrated in downstream areas (downstream Vu Gia, downstream Thu Bon, Vinh Dien, Ly ly, Truong Giang), which is caused by unsafe water supply (including including quantity and quality). For these areas, water shortage is due to lack of exploitation works.
\end{abstract}

Keywords: Vu Gia - Thu Bon River basin, MIKE HYDRO basin, water balance. 